\title{
0 que os brasileiros pensam acerca da velhice LGBT? Suas representações sociais
}

\author{
¿Qué piensan los brasileiros acerca de la vejez LGBT Seniors? \\ Sus representaciones sociales \\ What do Brazilians think about LGBT? Their Socials Representations
}

\author{
José Victor de Oliveira Santos* \\ Ludgleydson Fernandes de Araújo \\ Luciana Kelly da Silva Fonseca \\ Ana Gabriela Aguiar Trévia Salgado \\ Lorena Alves de Jesus \\ Universidade Federal do Delta do Parnaíba
}

Doi: https://doi.org/10.12804/revistas.urosario.edu.co/apl/a.5876

\section{Resumo}

A presente pesquisa buscou identificar e analisar as representações sociais da velhice LGBT entre brasileiros. A amostra foi composta por 1000 pessoas adultas da população brasileira em geral, com idade média de 27.5 anos $(\mathrm{DP}=9.25)$, sendo $64.9 \%$ mulheres. Utilizou-se entrevista estruturada que foi analisada a partir do programa Iramuteq, além de dados sociodemográficos. Nos resultados, a Classificação Hierárquica Descendente repartiu o corpus textual em quatro classes de proximidade representacional. Por um lado, representações sociais direcionadas a velhice LGBT como fase de solidão e sofrimento, que a sociedade ainda está conhecendo o fenômeno. Do outro, discussões baseadas em respeito, atenção e cuidado, além de velhice LGBT como uma conquista atribuída a felicidade. Discute-se que a diversidade amostral resulta nas diferentes representações sociais, e os dados revelam que a sociedade está se direcionando a compreender as diferenciações de gênero e orientação sexual na qual a velhice é uma fase na qual todos podem vivenciar.

Palavras-chave: envelhecimento; velhice LGBT; representações sociais.

\section{Resumen}

La presente investigación buscó identificar y analizar las representaciones sociales de la vejez LGBT entre

* Dirigir correspondência à José Victor de Oliveira Santos. ORCID ID: http://orcid.org/0000-0002-6661-2873. Universidade Federal do Delta do Parnaíba. Correio eletrônico: josevictorpsi@gmail.com

Para citar este artigo: Santos, J. V. O., Araújo, L. F., Fonseca, L. K. F., Salgado, A. G. A. T., \& Jesus, L. A. (2020). O que os brasileiros pensam acerca da velhice LGBT? Suas representações sociais. Avances en Psicología Latinoamericana, 38(2), 1-14. https://doi.org/10.12804/revistas.urosario.edu.co/apl/a.5876 
brasileros. La muestra estuvo compuesta por 1000 personas adultas de la población brasilera en general, con edad promedio de 27.5 años ( $\mathrm{DP}=9.25)$, de las que el $64.9 \%$ fueron mujeres. Se utilizó entrevista estructurada, que fue analizada a partir del programa Iramuteq, además de datos sociodemográficos. En los resultados, la Clasificación Jerárquica Descendiente repartió el corpus textual en cuatro clases de proximidad representacional. Por un lado, representaciones sociales direccionadas a la vejez LGBT como fase de soledad y sufrimiento, fenómeno que aún no es del todo conocido por la sociedad. Por el otro, discusiones basadas en respeto, atención y cuidado, además de vejez LGBT como una conquista atribuida a la felicidad. Se discute que la diversidad muestral resulta en las representaciones sociales, y los datos revelan que la sociedad está direccionándose a comprender las diferenciaciones de género y orientación sexual en la cual la vejez es una fase que todos pueden vivenciar.

Palabras clave: Envejecimiento; vejez LGBT; representaciones sociales.

\section{fbstract}

This research aimed to identify and analyze the social representations of old age LGBT among Brazilians. The sample consisted of 1000 adults from the Brazilian population in general, with a mean age of 27.5 years $(\mathrm{SD}=9.25), 64.9 \%$ of whom were women. A structured interview was used, and then analyzed from the Iramuteq program, in addition to sociodemographic data. In the results, the Descending Hierarchical Classification divided the textual corpus into four classes of representational proximity. On the one hand, social representations directed towards LGBT seniors as a phase of loneliness and suffering, which is a phenomenon not yet known by society. On the other, discussions based on respect, attention and care, in addition to senior LGBT as an achievement attributed to happiness. It is argued that sample diversity results in different social representations. The data revealed that society is moving towards understanding gender differentiation and sexual orientation in which old age is a phase in which all can experience.

Keywords: Aging; LGBT aging; social representations.
A velhice vem acarretando uma significativa repercussão política, social, psicológica e de saúde, juntamente a isto, a Geriatria e a Gerontologia intensificam sua atuação e metodologia, de forma a se adequar à esta problemática mundial (Camarano \& Kanso, 2010). Certamente, o crescimento da população idosa avança mais rapidamente do que a desconstrução de alguns mitos e estereótipos desta fase do desenvolvimento (Almeida \& Lourenço, 2010). O fato de ser idoso já traz em si diversos estigmas e muitas representações sociais negativas, que não corroboram com a percepção do envelhecimento na ótica de quem está na velhice, assim, a presença de senescência como fenômeno populacional, demonstra que alguns conceitos devem ser revistos socialmente (Silva, Lima \& Galhardoni, 2014).

As estatísticas registram que no Brasil 13\% da população é idosa, com a expectativa de vida de 75.8 anos segundo o Instituto Brasileiro de Geografia e Estatística (IBGE, 2015), que considera idosas as pessoas acima de 60 anos, por ser um país em desenvolvimento, como prega a Organização Mundial de Saúde (OMS, 2015). Quanto ao número de pessoas LGBT (lésbicas, gays, bissexuais, transgêneros, travestis, queers e intersexuais), estima-se que 17 milhões façam parte deste grupo (IBGE, 2015). A possibilidade de casamento e adoção são dois contribuintes para o aumento da população LGBT, haja vista que favorecerá a aceitação da orientação sexual e/ou identidade de gênero, possibilitando a formação de famílias homoparentais (Santos, Araújo, Negreiros \& Cerqueira-Santos, 2018).

O entendimento do envelhecimento a partir de uma perspectiva psicossocial foi negligenciado durante muito tempo. Ficar velho não era algo comum a toda população, porém, atualmente, a expansão do número de pessoas idosas está em evidência, tanto no Brasil, quanto no mundo (Mantovani, Lucca \& Neri, 2016). A perspectiva biológica do envelhecimento sempre prevaleceu sobre a social, os estudos sobre perdas e ganhos, vulnerabilidades, 
fragilidades físicas e mudanças físicas e no metabolismo passaram a ser mais reconhecidas na ciência e também no senso comum (Fechine \& Trompieri, 2012).

A pessoa idosa convive com estigmas e preconceitos que tornam alguns assuntos tabus, entre eles, a sexualidade (Solise \& Medeiros, 2016). A sexualidade vai além do ato sexual, e é neste ponto, que a sexualidade na velhice deve ser entedida como uma forma de trazer bem-estar físico e emocional, visto que, estudos registram que idosos atribuem a essência da sexualidade através do companheirismo, fantasias, desejo e das relações de afeto (Frugoli \& Magalhães, 2011; Solise \& Medeiros, 2016).

Mesmo que escassos, os estudos acerca da sexualidade na velhice prevalecem em torno da heterossexualidade (Araújo \& Carlos, 2018; Araújo \& Fernández-Rouco, 2016). Sabe-se que os idosos LGBT vivenciam estigmas e preconceitos tanto pela idade, quanto pela orientação sexual, sendo que os estudos a respeito deste tema ainda são pouco viabilizados. Entretanto, na última década, houve mais interesse por parte dos pesquisadores (Adams, 2015). A velhice LGBT é uma conquista de anos de luta, em que a militância foi fundamental para a redução da homofobia. Outro fato que contribuiu para a diminuição da mortalidade do público LGBT foi o conhecimento das formas de prevenção às infecções sexualmente transmissíveis (Mello, Brito, \& Maroja, 2012).

A cobrança por direitos nos poderes Executivo, Legislativo e Judiciário resultaram em algumas conquistas, mas sabe-se que a elaboração de estratégias de atenção básica a saúde e métodos protetivos devem ser implementados a fim de atender demandas específicas deste público, que vem aumentando a sua expectativa de vida (Fredriksen-Goldsen et al., 2013). Neste sentido, a criação do Plano Nacional de Promoção da Cidadania e Direitos Humanos de Lésbicas, Gays, Bissexuais, Travestis e Transexuais em 2009 e do Conselho Nacional LGBT em 2010 pelo governo brasileiro, são exemplos de ações desenvolvidas para desencadear melhorias para a população LGBT (Mello et al., 2012).
Em outra direção, os estereótipos negativos da sociedade retomam a dificuldade em que os idosos LGBT encontram em buscar ajuda em serviços públicos e privados (Cook-Daniels, 2015; Santos, Araújo, $\&$ Negreiros, 2019). As pessoas LGBT sentem-se retraídas pela sociedade, evitando manifestação dos atravessamentos que sua orientação sexual possibilita, em que, viver dentro do armário parece ser a melhor opção para os idosos LGBT (Orel \& Fruhauf, 2015). Negar a velhice, negar a orientação sexual, negar o gênero são fatos bem comuns na vida dos idosos LGBT, decerto o fato de que a segmentação que vivenciaram não demonstraram ser favoráveis às diversas identidades de gênero (Alves, 2010). Contrapõe-se a negação, o legado construído e repassado às outras gerações, que veio a acometer a integridade familiar, que traz segurança e apoio nas adversidades da vida (Marques \& Sousa, 2016). De fato, é razoável entender que na atualidade, os idosos têm maior possibilidade de vivenciar suas particularidades eróticas, se comparado ao século passado (Henning, 2017).

Compreender o perfil do idoso LGBT requer pensar no envelhecer a partir de diferentes experiências, costumes, identidades e saberes (Henning, 2017). Não se sintetizam características para tal grupo, mas estudos explanam algumas trajetórias e legados que formam a personalidade do idoso LGBT. Neste sentido, abordou-se aqui algumas perspectivas acerca do perfil dos idosos LGBT.

Em um estudo com idosas lésbicas, documenta-se que a sexualidade contribui para as manifestações afetuosas que complementam a relação de convívio, e mesmo que sintam seus corpos deixando de ter a rigidez e flexibilidade desejada, nada impede de terem relações sexuais (Alves, 2010). Além das mulheres lésbicas, as mulheres travestis tem certa preocupação com a estética do seu corpo, e cuidam de si constantemente, ainda que consigam estar fisicamente nos padrões, o preconceito existe, não por serem só idosas, e sim idosas travestis (Antunes \& Mercadante, 2011). Mesmo diante do preconceito, o respeito e admiração que as travestis 
conquistam com a sua forma de viver fundamenta o sucesso em chegar na velhice quebrando os tabus compartilhados socialmente.

Não característico apenas das mulheres, os homens também refletem os devaneios do corpo, a vergonha de si, como aborda Pocahy (2012), que circunda o contexto do corpo envelhecido como algo abjeto. Mesmo que a vivência sexual seja movida pela pulsão, os idosos gays necessitam de mais que isso, eles querem afeto, companhia, compartilhar histórias e outros fatos que tornam uma relação saudável e apaziguadora da rejeição do corpo em si mesmo (Pocahy, 2012). Um estudo aborda o fato de homens que vivem a maior parte da vida com mulheres e quando estavam próximos da velhice, divorciam-se e permitem a viver a homossexualidade que ocultaram dos outros durante toda uma vida (Santos \& Lago, 2013). É neste sentido que o desejo homoerótico em meio a uma sociedade que propaga a heteronormatividade como única manifestação sexual válida, impediu que muitas pessoas LGBT demonstrassem os devaneios que o sujeito necessita (Mota, 2012b).

Corroborando com os autores supracitados, Mota (2012a), usa o termo "sair do armário" e fala sobre a ausência de liberdade sexual, o que fez com que muitos gays não se permitissem vivenciar os seus desejos, e ao entrar na velhice, se encorajaram, mas com o receio de aceitação, não apenas da família, mas também do grupo LGBT, que sobremaneira excluem os ditos gays velhos, por não se enquadrarem no padrão pregado como atrativo. Assim como alguns se assumem ao entrar na velhice, outros se obrigam a voltar para o armário para poderem frequentar alguma instituição de longa permanência, em que as mesmas, postulam que lá não há sexualidade, apenas idosos. E com isso, que há uma representação de que idosos LGBT são solitários e frágeis (Passamani, 2013), quando na verdade se é oprimido para adequar-se a alguns padrões. Neste direcionamento, outro estudo desmitifica o sentido de que idosos LGBT são solitários, pelo contrário, muitos possuem cônjuges, alguns têm filhos (Fredriksen-Goldsen, Kim, Muraco \& Mincer, 2009).

Um estudo recente aborda a invisibilidade da velhice LGBT como um problema para a viabilização de políticas públicas específicas direcionadas ao público (Salgado, Araújo, Santos, Jesus \& Fonseca, 2017). São inúmeras as dificuldades vivenciadas pelos idosos LGBT que vivenciam a velhice em meio a conflitos internos e externos (Araújo \& Carlos, 2018; Silva \& Araújo, 2020). Eis então a importância deste estudo, sabendo da reduzida quantidade de estudos sobre o tema e que o fenômeno está em expansão mesmo diante de todas as dificuldades de ser LGBT.

Portanto, é de relevância acadêmica e social investigar a velhice LGBT para que haja a elaboração de políticas públicas que permitam a qualidade de vida deste público. De fato, a literatura demonstra o quanto o preconceito ocasiona a invisibilidade do idoso LGBT, e com isso, essa população fica desassistida pelos serviços de saúde, provocando a redução da longevidade. Um estudo na África do Sul relata que eles possuem uma riqueza em políticas públicas, mas na prática, essas políticas não funcionam devidamente (Reygan \& Henderson, 2019).

Diante deste referencial, reflete-se como a população brasileira visualiza o fenômeno do envelhecimento LGBT, em que a teoria das representações sociais é um instrumento para traçar as cognições e opiniões do senso comum e torná-los científicos. Sabe-se que o intuito da formação das representações é dar familiaridade aos temas e objetos (Oliveira, 2012), foi neste sentido, que Moscovici definiu as representações sociais como as formas de compreender, interpretar e compartilhar assuntos, que passam pelo processo de ancoragem e objetivação (Moscovici, 2017).

As representações sociais são formas de nomear e dar significado aos aspectos cotidianos, que envolve desde a percepção até a formação de atitudes, isto é, as maneiras de se posicionar diante de algum objeto (Jodelet, 2001). À medida que os 
sujeitos identificam algum objeto a ser representado socialmente, o mesmo ativa um critério que utiliza a afetividade, que é quando se julga negativamente ou positivamente algum fenômeno (Abric, 1998; Campos \& Rouquete, 2003). É neste ponto, que as representações sociais surgem como fontes organizadoras das ligações simbólicas de ordem individual e grupal (Coutinho, Araújo \& Saraiva, 2013). Os autores abordam ainda que, comparar as representações sociais do grupo a partir de uma dimensão societal é compreender a relação das relações sociais de interação, valores, atitudes e crenças. Diante do exposto, esta pesquisa teve como objetivo principal identificar e analisar as representações sociais da velhice LGBT entre brasileiros.

\section{Método}

Tipo da investigação: Trata-se de um estudo descritivo e exploratório com dados transversais.

\section{Participantes}

Contou-se com 1000 pessoas adultas da população brasileira em geral $(\mathrm{M}=27.5$ anos; $\mathrm{DP}=9.25)$, abrangendo os 26 estados e o Distrito Federal. Em sua maioria, do gênero feminino (64.9\%), com idades entre 18 e 63 anos. Quanto ao estado civil, 56.4\% pessoas solteiras, $18.4 \%$ casadas, $19.4 \%$ namorando, e com menos frequência, separados/divorciados (1.9\%), viúvos ( $1 \%)$, união estável (2.4\%) e outros $(0.5 \%)$. Referente a renda média mensal, $41.1 \%$ recebem até 1 salário mínimo, $28.1 \%$ entre 1 e 2 salários mínimos, $13.7 \%$ entre 2 e 3 salários mínimos, $6.2 \%$ entre 3 e 4 salários mínimos e por fim, $10.6 \%$ recebem acima de 4 salários mínimos. Na questão de religiosidade ou espiritualidade, consideram-se católicos (38.6\%), católicos não praticantes (12.1\%), evangélicos $(11.7 \%)$, agnósticos $(23 \%)$, espíritas (4.6\%), ateus $(6.3 \%)$, umbanda $(1.5 \%)$ e outras (2.2\%). Quanto a orientação sexual, $74.6 \%$ se consideram heterossexuais, $16.3 \%$ homossexuais, $7.7 \%$ bissexuais, assexuais $(0.5 \%)$ e pansexuais $(0.6 \%)$. $\mathrm{Na}$ escolaridade, $0.3 \%$ ensino fundamental, $16.2 \%$ ensino médio, $52.2 \%$ ensino superior incompleto, $14.1 \%$ ensino superior e $17.2 \%$ pós-graduação.

\section{Instrumentos}

Para caracterização dos participantes, utilizou-se questionário sociodemográfico, contendo perguntas como: idade, gênero, estado civil, religiosidade ou espiritualidade, renda individual média, escolaridade, orientação sexual, estado em que vive, se possui vínculo com pessoas LGBT e por último, se conhece algum idoso LGBT. Em seguida, utilizou-se uma pergunta aberta de forma a abarcar as representações sociais acerca da temática, sendo a pergunta: "como você entende a velhice LGBT?".

\section{Procedimentos éticos}

A presente pesquisa foi submetida ao Conselho de Ética em Pesquisa (CEP) da Universidade Federal do Piauí, apresentando CAEE: 57225916.1.0000.5214 e número do parecer: 1.755 .790 . O instrumento foi submetido a plataforma on-line do Google Docs e divulgado nas redes sociais e e-mails. Como critério de inclusão dos participantes, era necessário possuir idade $\geq 18$ anos. Durante a coleta de dados, foi explicitado que a participação seria voluntária e anônima, em seguida, foi apresentado o Termo de Consentimento Livre e Esclarecido (TCLE), explicando os objetivos e riscos da pesquisa. Após a confirmação do participante, o mesmo responde o protocolo e envia para o banco de dados on-line do Núcleo de Estudos e Pesquisa em Psicologia da educação, queixa escolar e desenvolvimento humano - Psiqued. Ressalta-se que foram seguidos todos os aspectos éticos regidos pelo Conselho Nacional de Saúde (CNS) do Brasil, disposto na Resolução 510/16. Foi explicado que o participante poderia desistir a qualquer momento. Para ser respondido, geralmente, levou-se em média 15 minutos. 


\section{Procedimentos de análise de dados}

Os dados obtidos com a entrevista estruturada foram analisados a partir do software IRAMUTEQ Interface de R Pour Analyses Multidimensionnelles de Textes et de Questionnaires (Camargo \& Justo, 2013; Nascimento \& Menandro, 2006; Ratinaud, 2009), que necessita do pacote do software R, que é um recurso de linguagem usada para análises estatísticas (R Development Core Team, 2011), estes dois programas realizam a análise dos três corpus textuais referentes as perguntas que estimulam a discussão acerca das temáticas desta pesquisa, o corpus é formado por linhas de comando seguidas das respostas, organizadas no editor de texto bloco de notas. Cada item é denominado Unidade de Contexto Inicial (UCI). Quanto às análises, foi realizado o procedimento de Classificação Hierárquica Descendente (CHD), que forma o dendograma, que aponta as classes lexicais em que foram divididas o discurso, a partir da frequência e do qui-quadrado $\left(X^{2}\right)$ (Reinert, 1990). Os aspectos sociodemográficos foram submetidos a análise descritiva a partir do programa estatístico IBM SPSS 23.

\section{Resultados}

A partir da CHD é possível a visualização das representações sociais acerca da velhice LGBT, em que o corpus textual se dividiu em quatro classes, em que se observa um amplo contexto representacional, que em muitas situações torna-se notório que as representações sociais da velhice LGBT estão ancoradas nos conceitos de envelhecimento e de homossexualidade, mesmo que o grupo LGBT esteja além da homossexualidade.

O corpus textual foi composto por $1000 \mathrm{UCI}$, que se tornaram 1046 Unidades de Contexto Elementar $\left(\mathrm{UCE}_{\mathrm{S}}\right)$, e 876 retidos para formar o corpus textual, sendo $83.75 \%$ com significância, com um total de 19.745 ocorrências de palavras, sendo que a média de palavras por $\mathrm{UCE}_{\mathrm{S}}$ era de 18.87. Para o dendograma, os vocábulos selecionados perpassaram o valor do qui-quadrado de $\geq 15.16$. As quatro classes foram separadas em dois subcorpus, as classes 1 e 2 fizeram parte do mesmo campo textual e as classes 3 e 4 no mesmo campo, sendo duas partições, como é possível observar na figura 1 .

A classe 1, denominada "pessoas felizes", foi composta por $29.34 \%$ das $\mathrm{UCE}_{\mathrm{s}}$, a variável descritiva que mais se destacou foi a de pessoas com ensino médio. Ressalta-se que a variável foi a mais significativa, mas não é a única variável presente na classe textual. Os dados revelam representações sociais embasadas no sentido de que é uma escolha na qual as pessoas buscam a felicidade em todas as fases da vida e na velhice se torna normal, as relações de querer, mostrar e gostar que vieram a construir em seu legado, enfatizando que não importa a orientação sexual, o envelhecimento é uma condição natural e tornar-se idoso seria a mostra de um envelhecimento bem sucedido, e além disto, as pessoas LGBT são consideradas pessoas alegres.

Os discursos dos participantes confirmam o direcionamento da classe, "são pessoas idosas que vivem felizes por terem feito essa escolha" (Participante 759, gênero masculino, 18 anos, solteiro, heterossexual, católico não praticante, ensino médio), e também, "algo mais que normal, pois não é porque são idosos que deixaram de sentir prazer e atração, seja pelo mesmo sexo, ou sexo oposto" (Participante 961, gênero feminino, 18 anos, namorando, heterossexual, evangélica, ensino médio), outra abordagem é que "a velhice é a idade avançada e cada um tem sua diretriz sexual" (Participante 769, gênero feminino, 30 anos, casada, heterossexual, católica, ensino médio). A palavra "escolha" reflete o pouco conhecimento sobre a gênese de ser LGBT, e nota-se que esse discurso reflete o desconhecimento do tema, o que possibilita a reprodução de preconceito.

A classe 2 foi composta por $14.95 \%$ das $\mathrm{UCE}_{\mathrm{S}}$, foi intitulada como "discussões de respeito" e não houve variável descritiva relevante. Para contextualização das representações sociais da velhice 
Classe 2

$131 \mathrm{UCEs}=14.95 \%$

Sem variável descritiva relevante

Discussões de respeito

\begin{tabular}{|l|c|c|}
\hline Palavra & $\mathrm{F}$ & $\mathrm{X}^{2}$ \\
\hline Respeito & 60 & 102.7 \\
\hline Precisar & 14 & 67.89 \\
\hline Atenção & 14 & 45.27 \\
\hline Merecer & 21 & 45.24 \\
\hline Carinho & 11 & 39.16 \\
\hline Cuidado & 21 & 37.29 \\
\hline Respeitado & 16 & 28.97 \\
\hline Dever & 109 & 28.81 \\
\hline Fase & 56 & 27.85 \\
\hline Ciclo & 7 & 27.78 \\
\hline Entender & 120 & 27.57 \\
\hline Discriminar & 10 & 24.1 \\
\hline Amor & 24 & 23.83 \\
\hline Respeitar & 21 & 23.7 \\
\hline Discussão & 4 & 22.85 \\
\hline Humano & 17 & 19.67 \\
\hline Saúde & 9 & 19.12 \\
\hline Etapa & 7 & 17.7 \\
\hline Discutir & 3 & 17.12 \\
\hline
\end{tabular}

Classe 1

257 UCEs $=29.34 \%$

Variável descritiva:

Ensino médio

Pessoas Felizes

\begin{tabular}{|l|c|c|}
\hline Palavra & $\mathrm{F}$ & $\mathrm{X}^{2}$ \\
\hline Feliz & 36 & 64.22 \\
\hline Escolha & 47 & 58.43 \\
\hline Sexo & 33 & 40.45 \\
\hline Avançado & 17 & 35.09 \\
\hline Normal & 57 & 33.64 \\
\hline Pessoa & 286 & 32.62 \\
\hline Amar & 15 & 30.15 \\
\hline Idade & 64 & 27.0 \\
\hline Querer & 29 & 26.85 \\
\hline Mostrar & 10 & 24.86 \\
\hline Gostar & 10 & 24.36 \\
\hline Travesti & 10 & 24.36 \\
\hline Escolher & 15 & 24.19 \\
\hline Jeito & 9 & 21.9 \\
\hline Importar & 11 & 20.37 \\
\hline Homem & 8 & 19.45 \\
\hline Lésbica & 8 & 19.45 \\
\hline Gosto & 10 & 17.96 \\
\hline Opinião & 9 & 15.96 \\
\hline Mulher & 9 & 15.56 \\
\hline Gay & 73 & 15.33 \\
\hline
\end{tabular}

Classe 4

$137 \mathrm{UCEs}=15.87 \%$

Variável descritiva:

Sexo masculino

Envelhecimento Solitário

\begin{tabular}{|l|c|c|}
\hline Palavra & $\mathrm{F}$ & $\mathrm{X}^{2}$ \\
\hline Solidão & 26 & 117.2 \\
\hline Filho & 15 & 57.3 \\
\hline Abandono & 11 & 36.29 \\
\hline Sozinho & 18 & 35.52 \\
\hline Preconceito & 151 & 34.64 \\
\hline Enfrentar & 19 & 32.63 \\
\hline Depender & 11 & 26.98 \\
\hline Sofrimento & 5 & 26.66 \\
\hline Depressão & 5 & 26.66 \\
\hline Aumentar & 5 & 26.66 \\
\hline Trato & 5 & 26.66 \\
\hline Mau & 5 & 26.66 \\
\hline Família & 7 & 25.79 \\
\hline Complicado & 17 & 23.96 \\
\hline Solitário & 23 & 23.32 \\
\hline Armário & 4 & 22.31 \\
\hline Neto & 4 & 21.31 \\
\hline Expor & 4 & 21.31 \\
\hline Adotar & 4 & 21.31 \\
\hline Maior & 20 & 17.86 \\
\hline Desafio & 12 & 16.44 \\
\hline Problema & 7 & 16.32 \\
\hline
\end{tabular}

Classe 3

349 UCEs $=39.84 \%$ Variável descritiva: Pessoas homossexuais Velhice e sexualidade

\begin{tabular}{|l|c|c|}
\hline Palavra & $\mathrm{F}$ & $\mathrm{X}^{2}$ \\
\hline Idoso & 169 & 69.51 \\
\hline LGBT & 150 & 62.75 \\
\hline Velhice & 208 & 40.28 \\
\hline Sociedade & 84 & 38.68 \\
\hline Conhecer & 34 & 34.57 \\
\hline Acreditar & 72 & 34.32 \\
\hline Dificuldade & 24 & 32.28 \\
\hline Sexualidade & 50 & 32.22 \\
\hline Jovem & 39 & 26.77 \\
\hline Preconceito & 151 & 24.05 \\
\hline Próprio & 24 & 23.39 \\
\hline Pensar & 36 & 22.54 \\
\hline Difícil & 59 & 20.63 \\
\hline Comunidade & 13 & 19.93 \\
\hline Imaginar & 26 & 18.73 \\
\hline Contato & 12 & 18.37 \\
\hline Tratar & 15 & 18.22 \\
\hline Atual & 15 & 18.22 \\
\hline Heteros- & 27 & 16.73 \\
sexual & 44 & 15.53 \\
\hline Assumir & 13 & 15.16 \\
\hline Realidade & & \\
\hline
\end{tabular}

Figura 1. Representações sociais da velhice LGBT entre brasileiros

LGBT nesta classe, é identificado o sentido de que a pessoa idosa necessita de respeito, carinho e atenção, pois a velhice é uma etapa da vida e ancora-se às representações sociais nos conhecimentos acerca do ser idoso. A "velhice LGBT é igual a de qualquer pessoa e o respeito deve prevalecer sobre tudo" (Participante 955, gênero feminino, 32 anos, solteira, heterossexual, agnóstica, ensino médio).

Além dessa abordagem fundamentada no respeito ao idoso por conta da idade, nesta classe, foi evidente o enquadramento de representações sociais fundamentadas no respeito ao longo da vida, por serem LGBT e estarem associadas ao convívio direto com o preconceito.
"O respeito deve existir independentemente da idade, pois a sexualidade permanece durante toda a vida, inclusive na velhice" (Participante 031, gênero masculino, 43 anos, homossexual, agnóstico, ensino superior). As classes 1 e 2 se complementam, e reproduzem representações sociais interligadas, cujos discursos debatem sobre a necessidade de que esses idosos têm de dispor políticas assistenciais de saúde voltadas às suas especificidades, pois mesmo que o envelhecimento seja comum à todas as pessoas, a subjetividade diferencia cada sujeito.

A classe 3, foi denominada como "velhice e sexualidade", composta por $39.84 \%$ das $\mathrm{UCE}_{\mathrm{s}}$, tendo pessoas homossexuais como a variável 
descritiva, parte do sentido de que os jovens LGBT estão chegando na velhice, e como a maioria dos participantes não conhecem idosos LGBT, precisamente, apenas $18.2 \%$ da amostra tem contato com algum idoso LGBT, então geralmente, abordam pelo entendimento que se têm de pessoas LGBT em geral. Como por exemplo, "nunca convivi com um idoso LGBT, acho que essas pessoas sentem-se retraídas em mostrar sua homossexualidade na sociedade, que oprime o idoso em diversos aspectos comportamentais, inclusive de sexualidade" (Participante 622, gênero feminino, 19 anos, solteira, bissexual, católica não praticante, ensino superior incompleto), trata-se ainda que, "os homossexuais de antigamente não se assumiam, portanto iremos conhecer isso futuramente" (Participante 269, gênero masculino, 29 anos, solteiro, heterossexual, católico, ensino superior), além disso, descreve-se que não haviam pensado nesta fase do desenvolvimento associado à orientação sexual e identidade de gênero. Outra questão de desconhecimento, é que pessoas LGBT podem ser de orientação heterossexual, o que diferencia é a identidade de gênero, e isso se acentua em parte das $\mathrm{UCE}_{\mathrm{s}}$, na qual utilizam o termo homossexual para tratar de pessoas LGBT.

Nesse contexto, percebe-se que o preconceito sexual, ageísmo e idadismo influenciam a baixa prevalência de idosos LGBT na sociedade, como dizem os participantes: "é um fator preocupante, uma conquista de muita luta e resistência, pela dificuldade em se viver em meio à homofobia" (Participante 629, gênero feminino, 23 anos, namorando, homossexual, ateísta, ensino superior incompleto). Destarte, documenta-se que os participantes sempre apontam a sociedade como preconceituosa, e que os fatores psicossociais dificultam que pessoas LGBT alcancem a velhice, e que a construção e prática de políticas públicas voltadas para esse público trará segurança e tranquilidade para seu envelhecimento.

Por último, a classe 4 , classificou $15.87 \%$ das $\mathrm{UCE}_{\mathrm{s}}$, como variável descritiva pessoas do gênero masculino, e o título "envelhecimento solitário".
As representações sociais dessa classe indicam o direcionamento à velhice como fase de solidão, abandono, sofrimento, desafio e problema, implicado no contexto de que pessoas LGBT não construíram família, logo vivem diante do desafio de viver sozinhos e excluídos, em que a exclusão parte do receio de sofrer preconceito da sociedade. Explanam ainda que são pessoas que passaram a vida "dentro do armário" e na velhice permitem vivenciar a sexualidade, o que os fazem enfrentar o preconceito até pelas próprias pessoas LGBT. O discurso a seguir fundamenta as representações sociais desta classe, observe:

\footnotetext{
Desconheço relatos de pessoas próximas a mim que são LGBT e idosas, mas sempre ouvi dizer que são pessoas solitárias, deprimidas e que se colocam em situações de risco de maneira constante, pois as redes de sociabilidade LGBT atuais não as aceitam em seu meio, por exemplo: boates, grupos de militância, redes sociais, entre outras. Essas pessoas, também me parecem que são colocadas na marginalidade por procurarem alternativas clandestinas de viver sua sexualidade como a procura pela prostituição, pois o culto à juventude que tem impregnado o universo LGBT não os aceita (Participante 260, gênero masculino, 30 anos, namorando, homossexual, pós-graduação).
}

Identifica-se um contexto de que a não aceitação da orientação sexual e identidade de gênero devido a opressão social que era muito mais intensa. E na velhice, é comum ocorrer uma descarga de arrependimento de não ter experienciado a sexualidade desde a juventude, e nesta fase do desenvolvimento resta a solidão e a busca do sexo com jovens. Numa sociedade que cultua a beleza jovem, ser idoso LGBT é sofrer duplamente (ser idoso e LGBT).

Destaca-se que as classes 1 e 2, apresentam-se mais positivas que as classes 3 e 4 , sendo possível visualizar nos dois subcorpus dois lados de representações sociais. Porém todas as classes demonstram o pouco conhecimento da velhice LGBT, reforçando 
a invisibilidade deste público. Mesmo com uma amostra ampla e com perfil de participantes diversificados, foi possível identificar as representações sociais da velhice LGBT entre brasileiros, sendo um país com população heterogênea.

\section{Discussão}

$\mathrm{O}$ ato de perceber um fenômeno desconhecido e atribuir significado a partir de conceitos compartilhados socialmente, nada mais é do que formar representações sociais, e assim, este estudo discute as representações sociais da velhice LGBT. Um tema emergente na sociedade, que por sua vez, apresenta conceitualizações focadas nos estigmas acerca da pessoa idosa e da pessoa LGBT. Estudos sobre envelhecimento registram que ser idoso é vivenciar mudanças biopsicossociais, com uma atenção voltada ao cuidado, respeito e particularidades subjetivas (Fechine \& Trompiere, 2012; Meneses et al., 2013; Torres, Camargo, Boulsfield \& Silva, 2015). Exprime-se ainda, a velhice como fase de descanso, solidão e dependência (Camarano \& Kanso, 2010; Frugoli \& Magalhães, 2011; Santos et al., 2018).

As pesquisas concernindo pessoas LGBT retratam um cenário de desconhecimento da dinâmica da vida de idosos LGBT, em que o discurso preconceituoso baseado em conceitos normativos e conservadores é propagado sem fundamento em dados da realidade (Brancaleoni, Vieira, Amorim $\&$ de Oliveira, 2016; Fialho, Nascimento \& Xerez, 2017; Pereira, Torres, Pereira \& Falcão, 2011; Rodrigues \& Ferro, 2012). Ao associar os dados dos estudos supracitados com os resultados deste estudo, identifica-se que as classes de representações sociais explanam, juntamente, conteúdos que são expressos separadamente, o preconceito sexual e os tabus frente ao idoso. A literatura relativa à velhice LGBT problematiza esse duplo preconceito (Antunes \& Mercadante, 2011; Araújo \& Fernandéz-Rouco, 2016; Santos, Carlos, Araújo \& Negreiros, 2017; Santos et al., 2018).
Neste sentido, nos resultados, os participantes possuem representações sociais de que a velhice é comum a todos, a diferença seria apenas na orientação sexual e identidade de gênero. Nota-se a frequência de representações sociais da velhice LGBT ancoradas nas representações sociais do envelhecimento. Um estudo realizado com idosos sobre suas representações sociais da velhice LGBT denota o desconhecimento de idosos LGBT, transmitindo a invisibilidade da velhice LGBT em sua própria coorte (Salgado et al., 2017). Uma pesquisa com universitários notificou dados semelhantes (Carlos, Santos \& Araújo, 2018). O fato é que a exemplo de pessoas transgêneros, a expectativa de vida é de apenas 35 anos (IBGE, 2016), correspondendo a um dos motivos da invisibilidade da velhice LGBT.

As representações sociais da velhice LGBT como fase feliz e normal, possivelmente advém de posicionamentos como o de estudos que mostram a velhice como uma fase feliz e de demonstração de respeito (Goldemberg, 2011; Neri et al., 2013), e de pessoas LGBT como gêneros alegres (Costa, 2011). Os estudos sobre velhice LGBT com enfoque em aspectos de felicidade se relacionam à gratidão (de Vries et al., 2019), por outro lado, constata-se o sentido de negação da velhice (Alves, 2010; Santos et al., 2017), e de busca do bem-estar através do autoconhecimento dos fatores de risco e proteção (Araújo \& Fernandéz-Rouco, 2016; Fredriksen-Goldsen et al., 2013).

Por outro lado, observa-se que as representações sociais do tema ainda estão se fundamentando, equivalendo a baixa existência de contato com idosos LGBT, cujos pesquisadores inferem que o número de idosos LGBT é pequeno, devido às infecções sexualmente transmissíveis e a dificuldade de acesso aos dispositivos de saúde, e também, devido a LGBTfobia (Cahill, 2015; Mello et al., 2012; Santos et al., 2017; Salgado et al., 2020). As representações sociais direcionadas ao sentido de solidão se elevam quando associadas à velhice LGBT, com o exacerbado pensamento de que essas pessoas não constituíram família e/ 
ou foram rejeitados pelos familiares (Passamani, 2013), além disto, idosos LGBT revelam dificuldades em construir laços afetivos na velhice (De Vries et al., 2019).

O idoso LGBT que teve o ápice da juventude no século XX, provavelmente vivenciou uma ditadura interna e externa de aceitação da sua sexualidade, e em muitos casos não se assumem, com o receio de discriminação, preconceito, maus tratos e violência física (Leal \& Mendes, 2017). Estes dados corroboram com os encontrados neste estudo, e isto é o conteúdo mais evidenciado na literatura sobre velhice LGBT (Henning, 2017; Passamani, 2013). Uma construção e validação de uma escala de atitudes frente à velhice LGBT constatou que os itens negativos possuíram maior significância (Medeiros, Araújo, Santos, Souza \& Monteiro, 2019).

Denota-se que a diversidade de representações sociais concernindo à velhice LGBT é reflexo da variedade amostral e registrar a partir de óticas diferenciadas traz a percepção de que existe preconceito, mas também compreensão e respeito. O estado atual do fenômeno da velhice LGBT demonstra que a sociedade está crescendo e a prevalência de pessoas LGBT está se elevando, mesmo diante da precariedade de ações em saúde voltadas para esse público e da presença de indivíduos com valores conservadores, moralistas e tradicionalistas irrefletidos.

\section{Considerações finais}

Assim como o perfil sociodemográfico dos participantes é amplo e distinto, as representações sociais da velhice LGBT apreendidas neste estudo se mostram diversas, e assim, foram identificados pensamentos positivos, negativos e até pessoas que passaram a pensar no assunto no momento em que aceitaram participar da pesquisa. O preconceito duplo é pouco acentuado no quesito de ser idoso, o fato de ser LGBT que predomina, as situações que ativam o preconceito não são fato de ser idoso ou LGBT, e sim as práticas sexuais.
Uma das classes representacionais descrevem sobre pessoas felizes, que remetem tanto ao sentido de que chegar na velhice já é um motivo de felicidade, quanto ao sentido de que pessoas LGBT são pessoas sempre felizes e animadas. Por outro lado, as representações sociais baseadas em solidão. Em outras classes, era frequente citar algo negativo e depois abordar algo positivo, sugere-se que seja desejabilidade social.

Os objetivos propostos neste estudo foram alcançados, e além dos objetivos, foi possível fazer 1000 pessoas refletirem acerca da temática, ampliando os olhares tanto dos participantes, quanto dos estudos sobre o estado atual da arte da velhice LGBT. Das dificuldades do estudo, têm-se o limitado acervo bibliográfico, a dificuldade de coletar e o fato de ser on-line fez com que universitários formassem a maioria da amostra. Não daria para generalizar os resultados à população brasileira, pela ampla diversidade cultural, porém as representações sociais registradas compuseram um pouco de várias realidades que são problemáticas no país.

Espera-se que este estudo sirva como subsídio para a elaboração de discussões pautadas nos direitos das pessoas LGBT, seja em capacitações profissionais, palestras, rodas de conversa e outros, o importante é fazer com que a sociedade tenha conhecimento sobre o fenômeno. Diante do crescimento populacional, a necessidade de políticas públicas voltadas a população idosa LGBT, e os dados aqui publicados, demonstram que mesmo com o preconceito, a sociedade já elabora pensamentos e tem posicionamentos, e para que a velhice LGBT não seja tratada como um tabu daqui há algumas décadas, os dados de realidade produzidos na ciência teriam que chegar até a população para o embasamento assertivo e respeitoso.

Contudo, espera-se que este estudo possa fundamentar novos construtos concernente à velhice LGBT, principalmente direcionado à amostras mais específicas, como por exemplo: profissionais da saúde e assistência social, idosos, entre diferentes religiões e posicionamento político, pessoas LGBT 
e idosos LGBT. Além de analisar a partir de outros construtos, como atitudes e percepção social. A conceitualização da velhice LGBT a partir de diversos construtos é o passo fundamental para a elaboração de metodologia que visem a qualidade de vida e longevidade do grupo.

\section{Referências}

Abric, J. C. (1998). A abordagem estrutural das representações sociais. Em A. S. P. Moreira \& D. C. Oliveira (Orgs.), Estudos interdisciplinares de representação social (pp. 27-38). Goiânia: $\mathrm{AB}$.

Adams, M. (2015). Foreword. Em N. A. Orel \& C. A. Fruhauf(Orgs.), The lives of LGBT older adults: Understanding challenges and resilience (pp. 01-02). Washington, DC: American Psychological Association.

Almeida, T., \& Lourenço, M. L. (2010). Reflexões: conceitos, estereótipos e mitos acerca da velhice. Revista Brasileira de Ciências do Envelhecimento Humano, 6(2), 233-444.

Alves, A. M. (2010). Envelhecimento, trajetórias e homossexualidade feminina. Horizontes Antropológicos, 16(34), 213-233.

Antunes, P. P. S., \& Mercadante, E. F. (2011). Travestis, envelhecimento e velhice. Kairós Gerontologia. Revista da Faculdade de Ciências Humanas e Saúde, 14(5), 109-132.

Araújo, L. F., \& Fernandéz-Rouco, N. (2016). Idosos LGBT: fatores de risco e proteção. Em D. V. S. Falcão, L. F. Araújo \& J. S. Pedroso (Orgs.), Velhices: temas emergentes nos contextos sociofamiliar, de saúde mental, cuidado e violência (pp. 22-32). Campinas, SP: Editora Alínea.

Araújo, L. F., \& Carlos, K. P. T. (2018). Sexualidade na velhice: um estudo sobre o envelhecimento LGBT. Psicología, Conocimiento y Sociedad, 8(1), 218-237.

Araújo, L. F., \& Silva, H. S. (2020). Velhice LGBT: apresentação de um panorama de estudos nacionais e internacionais. Em L. F. Araújo \&
H. S. Silva (Orgs.), Envelhecimento e Velhice LGBT: práticas e perspectivas biopsicossociais (pp. 15-43). Campinas: Alínea, 2020.

Brancaleoni, A. P. L., Vieira, F. S., Amorim, S. M. G., \& de Oliveira, R. R. (2016). Transitando por direitos: concepções de travestis do interior de São Paulo acerca de Direitos Humanos. Revista Periódicus, 1(5), 335-356.

Cahill, S. (2015). Community resources and government services for LGBT older adults and their families. Em N. A. Orel \& C. A. Fruhauf(Orgs.), The lives of LGBT older adults: Understanding challenges and resilience (pp. 141-169). Washington, D.C.: American Psychological Association.

Camarano, A. A., \& Kanso, S. (2010). As instituições de longa permanência para idosos no Brasil. Revista Brasileira de Estudos de População, 27(1), 232-235. Doi: http://dx.doi.org/10.1590/S010230982010000100014

Camargo, B. V., \& Justo, A. M. (2013). IRAMUTEQ: um software gratuito para análise de dados textuais. Temas em Psicologia, 21, 513-518. Doi: http://dx.doi.org/10.9788/TP2013.2-16

Campos, P. H. F., \& Rouquette, M. L. (2003). Abordagem estrutural e componente afetivo das representações sociais. Psicologia: reflexão e crítica, 16(3), 435-445.

Carlos, K. P. T., Santos, J. V. D. O., \& de Araújo, L. F. (2018). Representações sociais da velhice LGBT: estudo comparativo entre universitários de Direito, Pedagogia e Psicologia. Psicogente, 21(40), 297-320. Doi: https://doi.org/10.17081/ psico.21.40.3076

Cook-Daniels, L. (2015). Transgender aging: What practitioners should know. Em N. A. Orel \& C. A. Fruhauf (Orgs.), The lives of LGBT older adults: Understanding challenges and resilience (pp. 193-216). Washington, D.C.: American Psychological Association.

Costa, V. (2011). Revistas gays made in Brazil, mas com sotaque estrangeiro. Revista Gênero, 12(1), 183-212. 
Coutinho, M., Araújo, L., \& Saraiva, E. (2013). Revisitando a teria das representações sociais: uma abordagem teórica. Em R. Cruz \& E. Gusmão (Orgs), Psicologia: conceitos, técnicas e pesquisas: volume II (pp. 11-23). Curitiba: Editora CRV.

De Vries, B., Gutman, G., Humble, Á., Gahagan, J., Chamberland, L., Aubert, P., ..., Mock, S. (2019). End-of-life preparations among LGBT older canadian adults: The missing conversations. The International Journal of Aging and Human Development, 88(4), 1-22. Doi: https:// doi.dx.org/10.1177/0091415019836738

Fechine, B. R. A., \& Trompieri, N. (2012). O processo de envelhecimento: as principais alterações que acontecem com o idoso com o passar dos anos. InterSciencePlace, 1(20), 106-132.

Fialho, L. M. F., Nascimento, L. B. S., \& Xerez, A. S. P. (2017). O que as professoras da educação básica sabem sobre gênero? Cadernos e Pesquisa: Pensamento Educacional, 11(27), 63-79.

Fredriksen-Goldsen, K. I., Emlet, C. A., Kim, H. J., Muraco, A., Erosheva, E. A., Goldsen, J., \& Hoy-Ellis, C. P. (2013). The physical and mental health of lesbian, gay male, and bisexual (LGBT) older adults: The role of key health indicators and risk and protective factors. The Gerontologist, 53, 664-675.

Fredriksen-Goldsen, K. I., Kim, H. J., Muraco, A., \& Mincer, S. (2009). Chronically ill midlife and older lesbians, gay men, and bisexuals and their informal caregivers: The impact of the social context. Sexuality Research \& Social Policy, 6, 52-64.

Frugoli, A., \& Magalhães, C. A. O. (2011). A sexualidade na terceira idade na percepção de um grupo de idosas e indicações para a educação sexual. Arquivos de Ciências da Saúde da UNIPAR, 15, 85-93.

Henning, C. E. (2017). Gerontologia LGBT: velhice, gênero, sexualidade e a constituição dos "idosos LGBT". Horizontes Antropológicos, 23(47), 283-323. Doi: http://dx.doi.org/10.1590/s010471832017000100010
Instituto Brasileiro de Geografia e Estatística - IBGE. (2016). Tábua completa de mortalidade para o Brasil-2014. Breve análise da evolução da mortalidade no Brasil. Brasília: IBGE.

Instituto Brasileiro de Geografia Estatística - IBGE. (2015). Pesquisa nacional por amostra de domicílios: síntese de indicadores 2014. Coordenação de trabalho e rendimento. Rio de Janeiro: IBGE. Disponível em http://biblioteca.ibge.gov.br/visualizacao/livros/liv94935.pdf

Jodelet, D. (2001). Representações Sociais: um domínio em expansão. Em D. Jodelet (Org.), Tradução Lílian Ulup, As representações sociais (pp. 17-44). Rio de Janeiro: Editora da UERJ.

Leal, M. D. G. S., \& Mendes, M. R. O. (2017). A geração duplamente silenciosa-velhice e homossexualidade. Revista Portal de Divulgação, 51(7), 18-35.

Mantovani, E. P., Lucca, S. R. D., \& Neri, A. L. (2016). Associações entre significados de velhice e bem-estar subjetivo indicado por satisfação em idosos. Revista Brasileira de Geriatria Gerontologia, 19(2), 203-222.

Marques, F. D., \& Sousa, L. (2016). Portuguese older gay men: Pathways to family integrity. Paidéia (Ribeirão Preto), 26(64), 149-159.

Medeiros, E. D., Araújo, L. F., Santos, J. V. O., Souza, T. C., \& Monteiro, R. P. (2019). Attitudes towards Lesbian, Gay, Bisexual and Transgender Old Age Scale (EAFV- LGBT): Elaboration and psychometric evidence. The Spanish Journal of Psychology, 22(e14), 1-8. Doi: https://doi. dx.org/10.1017/sjp.2019.14

Mello, L., Brito, W., \& Maroja, D. (2016). Políticas públicas para a população LGBT no Brasil: notas sobre alcances e possibilidades. Cadernos Pagu, (39), 403-429.

Meneses, D., Júnior, F., Melo, H., Silva, J., Luz V., \& Figueiredo, M. (2013). A dupla face da velhice: o olhar de idosos sobre o processo de envelhecimento. Enfermagem em Foco, 4(1), 15-18.

Moscovici, S. (2017). Representações Sociais: investigações em Psicologia Social. Petrópolis: Vozes. 
Mota, M. P. (2012a). "Ao sair do armário encontrei a velhice": a homossexualidade masculina e a experiência de envelhecer. Revista Praia Vermelha, Rio de Janeiro, 22(1), 133-144.

Mota, M. P. (2012b). A construção da homossexualidade no curso da vida a partir da lembrança de gays velhos. Bagoas-Estudos gays: gêneros e sexualidades, 6(7), 199-222.

Nascimento, A. R. A., \& Menandro, P. R. M. (2006). Análise lexical e análise de conteúdo: uma proposta de utilização conjugada. Estudos e Pesquisas em Psicologia, 6(2), 1-17.

Neri, A. L., Borim, F.S.A., Ribeiro, L. H. M., Rabelo, D. F., Melo, D. M., Pinto, J.M., Reis, M., Held, R. B., Pacagnella, A. B. B., \& Lopes, L. O. (2013). O que os idosos entendem por velhice saudável e feliz. Em A. L. Neri (Org.), Fragilidade e qualidade de vida na velhice. Dados do Estudo Fibra (pp. 341-363). Campinas: Alínea.

Oliveira, M. (2012). O conceito de representações coletivas: uma trajetória da divisão do trabalho às formas elementares. Debates do NER, 2(22), 67-94.

Orel, N. A., \& Fruhauf, C. A. (2015). The lives of LGBT older adults: Understanding challenges and resilience. Washington, D.C.: American Psychological Association.

Organização Mundial da Saúde - OMS. (2015). Relatório mundial sobre violência e saúde. Genebra: Organização Mundial da Saúde. Disponível em http://sbgg.org.br/wp-content/uploads/2015/10/ OMS-ENVELHECIMENTO-2015-port.pdf

Passamani, G. R. (2013). Velhice, homossexualidades e memória: notas de campo no Pantanal sul-matogrossense. Disponível em http://www. fg2013.wwc2017.eventos.dype.com.br/resources/anais/20/1381508577_ARQUIVO_GuilhermeRPassamani.pdf

Pereira, C. R., Torres, A. R. R., Pereira, A., \& Falcão, L. C. (2011). Preconceito contra homossexuais e representações sociais da homossexualidade em seminaristas católicos e evangélicos. Psicologia: Teoria e Pesquisa, 27(1), 73-82.
Pocahy, F. (2012). A velhice como performativo: dissidências (homo) eróticas. Ex Aequo, (26), 43-56.

R Development Core Team. (2011). R: A language and environment for statistical computing. Vienna, Austria: R Foundation for Statistical Computing.

Ratinaud, P. (2009). IRAMUTEQ: Interface de R pour les Analyses Multidimensionnelles de Textes et de Questionnaires [Computer software]. Disponível em http://www.iramuteq.org

Reinert, M. (1990). Alceste: une methologie d'analyse dês donnees textualles et une application. Bulletin de Méthodologie Sociologique, 28, 24-54.

Reygan, F., \& Henderson, N. (2019). All bad? Experiences of aging among LGBT elders in South Africa. The International Journal of Aging and Human Development, 88(4), 1-17. Doi: https:// doi.org/10.1177/0091415019836929

Rodrigues, M., \& Ferro, L. F. (2012). Saúde e população LGBT: demandas e especificidades em questão. Psicologia: Ciência e Profissão, 32(3), 552-563.

Salgado, A. G. T. S., Araújo, L. F., Santos, J. V. O., Jesus, L. A., \& Fonseca, L. K. (2017). Velhice LGBT: uma análise das representações sociais entre idosos brasileiros. Ciencias Psicológicas, 11(2), 155-163. Doi: https://dx.doi.org/10.22235/ cp.v11i2.1487

Salgado, A. G. A. T., Araújo, L F., Santos, J. V. O., Jesus, L. A., Gomes, H. V., \& Araújo, M. M. (2020). Diferentes crenças religiosas e suas concepções psicossociais sobre a velhice LGBT. Em L. F. Araújo \& H. S. Silva (Orgs.), Envelhecimento e Velhice LGBT: práticas e perspectivas biopsicossociais (pp. 185-196). Campinas: Alínea, 2020.

Santos, D. K. D., \& Lago, M. C. D. S. (2013). Estilísticas e estéticas do homoerotismo na velhice: narrativas de si. Sexualidad, Salud y Sociedad, 6(15), 113-147.

Santos, J. V. O., Araújo, L. F., \& Negreiros, F. Atitudes e estereótipos em relação a velhice LGBT. Interdisciplinar-Revista de Estudos em Lingua e Literatura, 29(1), 57-69. Disponível em https:// 
seer.ufs.br/index.php/interdisciplinar/article/ view/9624/7457

Santos, J. V. O., Araújo, L.F., Negreiros, F., \& Cerqueira-Santos, E. (2018). Adoção de crianças por casais homossexuais: As representações sociais. Temas em Psicologia, 26(1), 139-152. Doi: http://dx.doi.org/10.9788/tp2018.1-06pt

Santos, J. V. O.; Carlos, K. P. T.; Araújo, L. F. \& Negreiros, F. (2017). Compreendendo a velhice LGBT: uma revisão da literatura. Em L. F. Araújo \& C. M. R. G. Carvalho (Org.), Envelhecimento e práticas gerontológicas. (pp. 81-96). Curitiba: Editora CRV.
Silva, H. S. D., Lima, Â. M. M. D., \& Galhardoni, R. (2014). Envelhecimento bem-sucedido e vulnerabilidade em saúde: aproximações e perspectivas. Interface - comunicação, saúde e educação, 8, 11-18.

Solise, V. O., \& de Medeiros, M. P. (2016). Sexualidade na velhice. Disciplinarum Scientia| Saúde, 3(1), 165-180.

Torres, T., Camargo, B., Boulsfield, A., \& Silva, A. (2015). Representações sociais e crenças normativas sobre envelhecimento. Ciência \& Saúde Coletiva, 20(12), 3621-3630. 